who were kind enough to communicate with me. You and they will, no doubt, be pleased to learn that, following my representation, the authorities have issued an order prescribing the use of silencers for motor cycles after March 31st next, and have informed me that borough and county councils are empowered under Section 23 Municipal Corporation Act, 1882, Section 16 Local Government Act, 1888, and Section 5 London Government Act, 1899, to make by-laws dealing with the other noises complained of.

$$
\text { I am, Sir, yours faithfully, }
$$

Chas. Monk,

Lientenant-Colonel, I.M.S. (retired). Burlton Lodge, Station-road, Barnes, S.W., Nov. 25th, 1912.

\section{CATTLE AND HORSES AS TYPHOID CARRIERS.}

To the Editor of THE LANCET.

SiR,-Practising as I have been for the last 24 years in South Africa, I have been often struck with the way enteric fever spreads, apparently without any regard for timehonoured principles. I have had experience of several epidemics, and I think it may be useful to put certain ideas of mine on paper, which are the result of observation, and which may explain the apparently erratic behaviour of this disease. Even if the explanation should turn out to be incorrect or inaccurate, it might at any rate lead to further observation on a line which, as far as I am aware, has not been suggested-namely, that cattle, horses, and perhaps other animals may be typhoid carriers.

When I first started practice in Clanwilliam in the early part of 1888 the country was flooded by the heaviest rains that had occurred in the memory of the proverbial oldest inhabitant. Typhoid fever had made a start before the rain, however, had begun, continued more or less during: the rainy season, but assumed its greatest severity as the dry weather set in. I was then quite unable to account for its spread and severity, the farms being isolated dwellings often at a considerable distance from one another. Its greatest intensity was along the course of the Oliphants River, but as the river water was not used for drinking or household purposes, and was a large rapidly flowing stream, I did not think the river could be to blame. Drinking water was obtainer from mountain springs that ran down and collected into furrows from which all water for household use and irrigation was drawn. The doctrine of typhoid carriers was unknown or known to but few, and the idea of " carrying" by means of cattle had never occurred to me.

The next severe outbreak that I had to deal with was during the concluding stages of the war--that is to say, from January, 1901, until September or October, 1902, when the country was still being largely policed. Then I noticed how typhoid fever occurred constantly in the neighbourhood of remount camps or in places where large numbers of horses had congregated and where manure in large quantities was lying about the ground, and I came to the conclusion that horse-dung probably made an excellent culture medium for the typhoid bacillus, and was carried by flies from place to place.

Within the last few days I was sent by the Divisional Council to investigate an outbreak that had occurred on two farms about 50 miles from Clanwilliam; the farms were about four miles from each other. On the first farm I found two European children suffering from the disease. The orners of the farm were cleanly, intelligent Dutch people, and they used every precaution to prevent the spread of the disease. The second farm, however, was quite different. Not only were the inhabitants uncleanly and careless, but the houses were built on a marsh with water flowing all about them, and it was upon this farm that the disease originated. Here $I$ found in all eight cases in different stages. The water-supply in both cases, as stated before, was from a mountain spring where cattle were in the habit of drinking, and the water, after being contaminated with their fæces, was freely used for household purposes. At the time of the present outbreak there was no enteric fever in the neighbourhood, and the idea struck me that possibly some of the cattle might be carriers, who deposit the bacillus in a suitable medium for its growth, and are thus able to start an outbreak of enteric ferer in the neighbourhood.
I remember that during the war the spread of enteric fever could not always be accounted for, and from time to time I have thought that possibly horses, cattle, and other animals, who do not suffer themselves from the disease, might be able to carry it and deposit its bacilli in various places. If this view be correct, it would readily explain the apparently erratic behaviour which characterises so many of the South African epidemics.

I should be glad if you would give publicity to this, if you think it would create discussion, as it is a question of considerable importance to South Africa, where typhoid fever epidemics often assume a very serious character.

I am, Sir, yours faithfully,

ALFRED A. HAYES,

Clanwilliam, Cape Province, South Africa. District Surgeon.

\section{THE ADVISORY COMMITTEE UNDER THE NATIONAL INSURANCE ACT. \\ To the Editor of THE LANCET.}

SIR,...The numerous letters I have received from members of the medical profession and the announcement of Sir John Collie's resignation make it necessary for me to explain my attitude towards the Advisory Committee of the National Health Insurance Act. I did not respond to the request of the British Medical Association that I should resign for two reasons. The Association had accepted sanatorium benefit, and I was placed on the committee chiefly for the purpose of advising with regard to the regulations of that benefit. Further, I thought it my duty to remain on the committee so long as there appeared to be any hope of the Chancellor of the Exchequer coming to some arrangement which would satisfy the legitimate and reasonable demands of the profession.

In view of the terms of the British Medical Association's resolution of Nov. 20th, which is now before the Chancellor and which does not preclude the possibility of a settlement, I feel it to be my duty to continue to serve on the committee until the Association finds that it is unable to obtain satisfaction for what it authoritatively defines as the reasonable demands of the profession.

I am, Sir, yours faithfully,

Portland-place, W., Nov. 21st, $1912 . \quad$ ARTHUR LATHAMr.

\section{FIRE PROTECTION IN LONDON AND THE LONDON COUNTY COUNCIL.}

\author{
To the Editor of THE LANCET.
}

SIR,-The coroner in summing-up at the Kensington fire inquest on Nov. 21st, is reported to have spoken as follows :-

The calamity made one wonder how many other buildings in London were in the same condition as they were told Messrs. Barkers premises were; how the many negotiations were going on, and how many buildings were waiting before the necessary alterations were to be made.

I wish to take the earliest opportunity of publicly replying: to these questions. There are upwards of 50,000 building's in the metropolis at the present moment to which the London Building Act Amendment Act of 1905 has not yet been applied. Although this Amendment Act has been in force now for upwards of seven years, the superintending architect of the London County Council, giving evidence before the House of Commons Committee on the London County Council General Powers Bill (1912) in June last, stated that only 2330 buildings had been scheduled for action at that date, and that the Building Act Committee of the London County Council had only considered 1203 of those cases. Of these 1203 cases only 527 had at that date been satisfactorily equipped by the provision of suitable means of escape, and the balance were in what might be termed a state of negotiation.

That so few buildings (527) should have been put in order out of approximately 50,000 cases in the long period of seven years is a matter of the gravest import, but the blame sbould not in any way be attributed to the superintending architect nor his officers, but specifically to the London County Council in its corporate capacity, which does not give its Building Act department the necessary means, the necessary staff, or the necessary encouragement to carry 